\title{
VISUALISASI POTENSIAL LISTRIK DI ANTARA DUA PLAT SEJAJAR BERHINGGA DENGAN PROGRAM KOMPUTER BERBASIS MATLAB
}

\author{
Eviliony $^{1, *}$, Erwin $^{2}$, Antonius Surbakti $^{2}$ \\ ${ }^{1}$ Mahasiswa Program Studi - S1 Fisika \\ ${ }^{2}$ Dosen Jurusan Fisika \\ Fakultas Matematika dan Ilmu Pengetahuan Alam \\ Universitas Riau Pekanbaru \\ Kampus Bina Widya J1. Prof. Dr. Muchtar Luthfi \\ Panam Pekanbaru 28282, \\ *E-mail: evi.lionybakara@gmail.com
}

\begin{abstract}
The calculation of electric potential between two parallel plates with finite size is difficult work, visualization of the issue comprehensively is needed. In this paper, visualization of electric potential between two parallel plates with finite size has been done by developing a MATLAB based computer program. The electric potential was calculated by solving two dimensional Laplace equation. There are two parts of the program that have been developed, the menu program and the main program. The menu program was provided to store the input data required in the calculation. While, the main program served toperform calculations and visualization of the electric potential. The visualization of the electric potential was shown in the mesh and contour graph. The results showed that the program is applicable for various sizes of plates, and the electric potential in each position can be calculated and visualized. However, the computer programs has some limitations, such as for perfoming calculations of electric potential. For plate width (b) of $50 \mathrm{~m}$, distance of plates (u) of $1 \mathrm{~m}$, and initial potential $\left(V_{0}\right)$ of 70 Volt, the electric potential in coordinate $(20,0.5)$ is not defined $(N a N)$.
\end{abstract}

Keywords: MATLAB, Laplace equation, electric potential, 2 dimensional plate, visualization.

\begin{abstract}
ABSTRAK
Perhitungan potensial listrik di antara dua plat sejajar merupakan persoalan yang sulit, sehingga dibutuhkan visualisasi agar pemahaman terhadap persoalan tersebut lebih komprehensif. Pada penelitian ini, dilakukan visualisasi terhadap potensial listrik diantara dua plat sejajar yang ukurannya berhingga. Potensial listrik dihitung dengan menyelesaikan persamaan Laplace dalam koordinat kartesian 2-D. Visualisasi dibuat dengan menggunakan software MATLAB. Ada dua program yang telah dibuat, yaitu program menu dan program utama. Program menu berfungsi untuk menginputkan parameter yang diperlukan dalam perhitungan, sementara program utama berfungsi untuk melakukan perhitungan dan visualisasi potensial listrik. Visualisasi potensial listrik ditampilkan melalui grafik mesh dan contour. Hasil simulasi menunjukkan bahwa program yang telah dibuat dapat digunakan untuk ukuran plat yang berbeda dan potensial listrik setiap titik dapat ditentukan dan divisualisasikan. Namun, program komputer yang dibuat ini memiliki keterbatasan untuk melakukan perhitungan terhadap potensial listrik untuk persoalan ini. Untuk lebar plat $(b)=50 \mathrm{~m}$, jarak antar plat $(u)=1 \mathrm{~m}$ dan potensial awal $\left(V_{\square}\right)=70$ Volt, potensial listrik pada titik koordinat $(20,0.5)$ tidak terdefinisi $(\mathrm{NaN})$.
\end{abstract}

Kata kunci: MATLAB, persamaan Laplace, potensial listrik, plat 2-D, visualisasi.

\section{PENDAHULUAN}

Salah satu bentuk sederhana dari persamaan diferensial parsial adalah persamaan Laplace. Persamaan ini merupakan salah satu jenis persamaan diferensial parsial tipe eliptik. Pada hakikatnya persamaan Laplace adalah persamaan Poisson untuk kasus tanpa sumber $(\rho=0)$ seperti muatan. Persamaan Laplace dapat digunakan untuk menjelaskan peristiwa potensial listrik [1]. Penyelesaian persamaan Laplace melibatkan koordinat seperti koordinat kartesian, silinder dan bola sesuai dengan kondisi fisis persoalan yang ditinjau. 
Persoalan potensial listrik dapat diselesaikan dengan metode pemisahan variabel (separation of variables). Pada metode ini, solusi persamaan diferensial parsial adalah hasil perkalian dari masingmasing fungsi yang hanya bergantung pada satu variabel [2].

Visualisasi potensial listrik perlu dilakukan agar pemahaman seseorang akan persoalan tersebut lebih komprehensif [3]. MATLAB merupakan program matematis yang dapat digunakan untuk melakukan komputasi, pemograman, visualisasi dan pengolahan database [4]. Sehingga pada penelitan ini dilakukan perhitungan dan visualisasi potensial listrik diantara dua buah plat sejajar berhingga yang terpisah sejauh $a$ dengan menggunakan software MATLAB.

\section{LANDASAN TEORI}

Potensial listrik didefenisikan sebagai energi potensial per satuan muatan positif. Potensial listrik dapat ditulis sebagai persamaan berikut:

$$
V=\frac{U}{Q}
$$

Persamaan Laplace merupakan salah satu jenis persamaan diferensial parsial tipe eliptik. Pada hakikatnya persamaan Laplace adalah persamaan Poisson untuk kasus tanpa sumber $(\rho=0)$ seperti muatan. Persamaan Laplace dapat ditulis sebagai berikut:

$$
\nabla^{2} V=0
$$

Menurut Griffiths (1999), dua buah plat sejajar yang berjarak $a$ satu sama lain melebar dari $x=0$ sampai $x=\infty$, jika diberikan potensial konstan $V_{\mathrm{u}}$ pada $x=0$ maka potensial listrik diantara dua plat tersebut dihitung dengan menyelesaikan persamaan Laplace [4]. Adapun syarat batas yang diberikan pada persoalan ini adalah sebagai berikut:

$$
V(x, 0)=V(x, a)=V(\infty, y)=0, V(0, y)=V_{0}
$$

Sehingga potensial listrik yang didapatkan adalah:

$$
V(x, y)=\frac{4 V_{0}}{\pi} \sum_{n=1.3,5 \ldots} \frac{1}{n} e^{-n \pi x / a} \sin (n \pi y / a)
$$

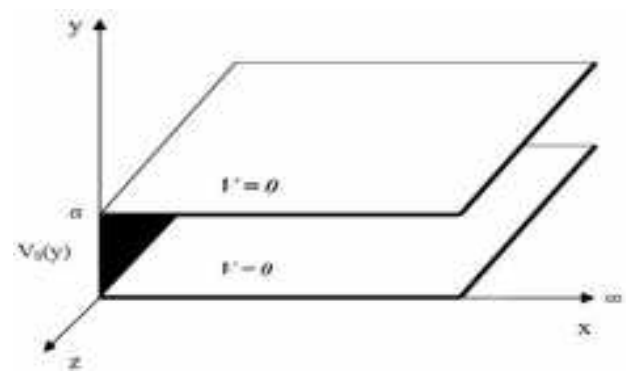

Gambar 1. Potensial listrik diantara dua buah plat sejajar tidak berhingga.

Namun, jika lebar plat pada persoalan tersebut dibatasi, yaitu $x=b$ maka Persamaan (4) bukan solusi yang tepat. Solusi yang tepat didapatkan dengan menyelesaikan kembali persamaan Laplace pada koordinat kartesian sesuai syarat batas yang barusehingga didapatkan solusi akhir potensial listrik sebagai berikut:

$$
V(x, y)=-\frac{4 V_{0}}{\pi} \sum_{n=1,3, \ldots} \frac{1}{n} \sin \frac{n \pi y}{a} \frac{\sinh \frac{n \pi(x-b)}{a}}{\sinh \frac{n \pi b}{a}}
$$

\section{METODOLOGI PENELITIAN}

Perhitungan potensial listrik diantara dua buah plat logam dilakukan dengan terlebih dahulu menyelesaikan persamaan Laplace. Persamaan Laplace diselesaikan secara analitik berdasarkan syarat batas yang berhingga. Solusi akhir persamaan Laplace diuji untuk beberapa syarat batas, kemudian dilakukan perhitungan dan visualisasi terhadap potensial listrik.

Gambar 2 adalah diagram alir yang menunjukkan prosedur yang dilakukan pada penelitian ini: 


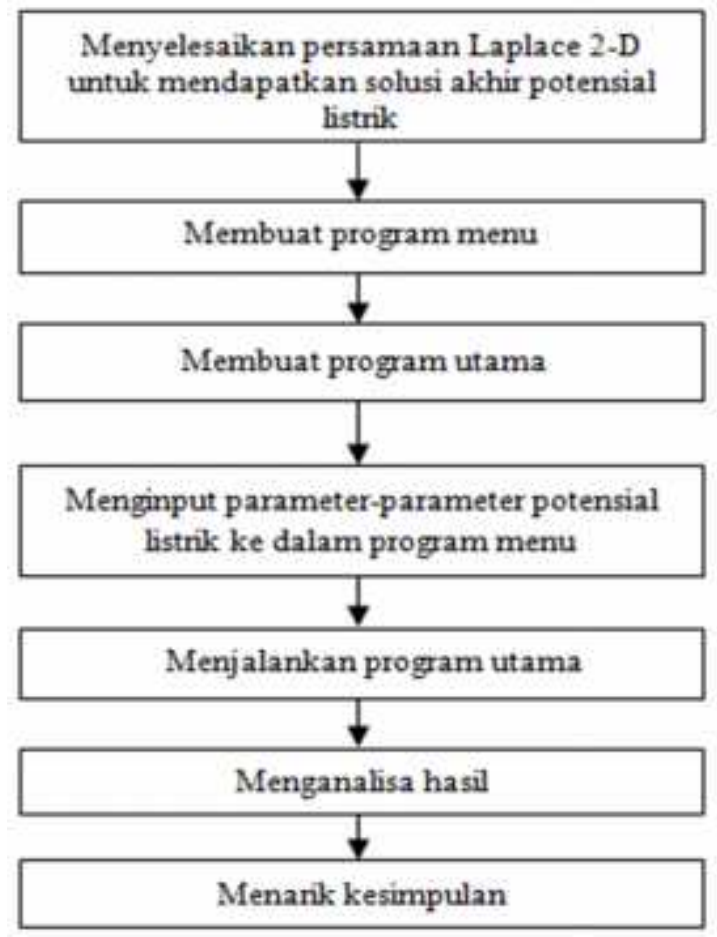

Gambar 2. Prosedur penelitian.

\section{HASIL DAN PEMBAHASAN}

\section{Program menu}

Program menu adalah program yang berfungsi untuk memudahkan pengguna dalam penginputan parameter-parameter yang dibutuhkan dalam perhitungan potensial listrik. Program menu dirancang menggunakan media tampilan grafis yaitu Graphical User Interface (GUI) sehingga tampilan program lebih atraktif dan mudah digunakan dan disimpan dengan ekstensi fig .

Gambar 3 adalah tampilan dari program menu yang dibuat menggunakan GUI.

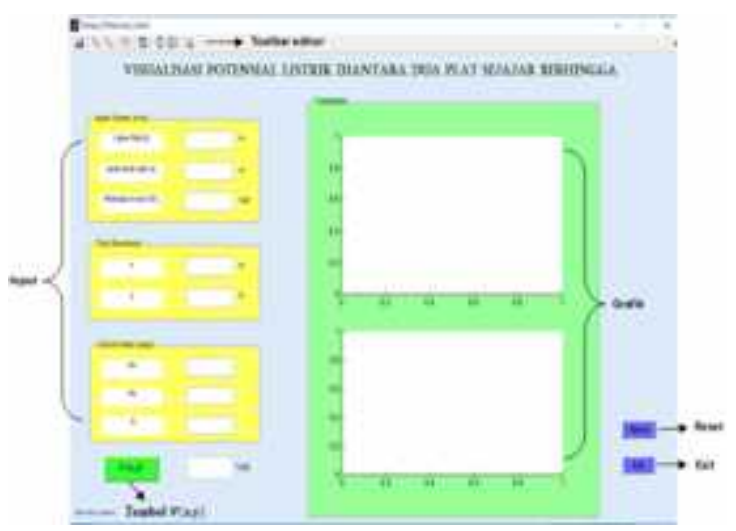

Gambar 3.Tampilan program menu.

\section{Program utama}

Program utama berisi sederetan perintah yang disusun secara berurutan untuk melakukan perhitungan dan visualisasi potensial listrik diantara dua plat sejajar. Program utama bekerja dengan memanggil data yang telah diinput pada program menu.

Gambar 4(a) sampai dengan 4(e) yang menunjukkan visualisasi potensial listrik untuk eksperimen I hingga $\mathrm{V}$ melalui grafik mesh dan contour:

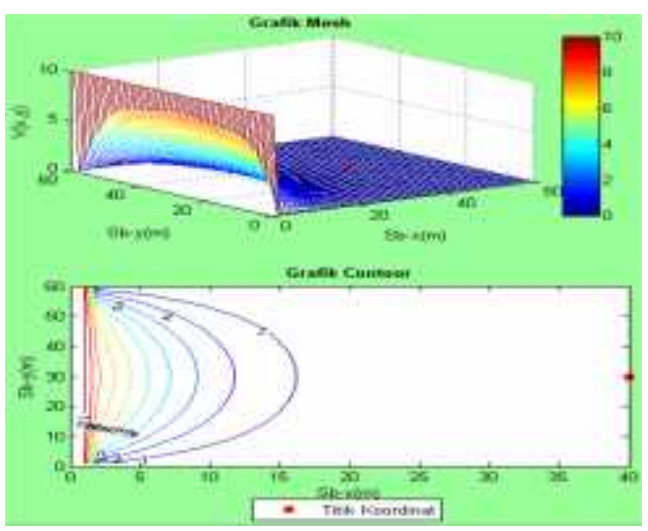

(a)

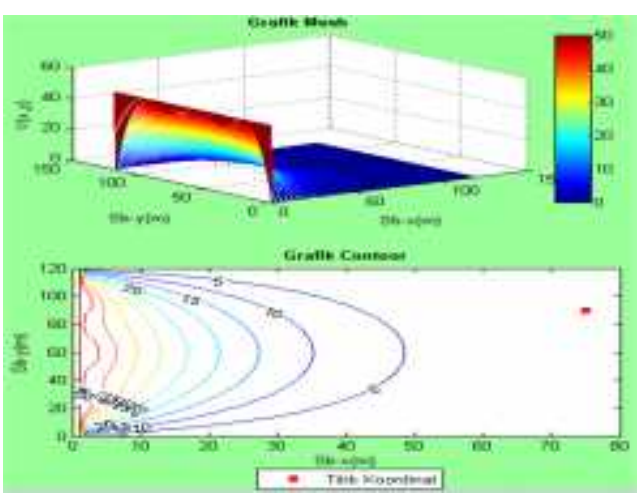

(b)

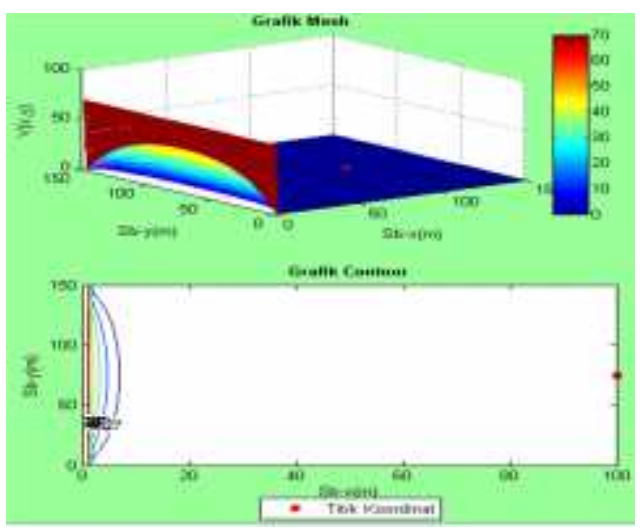

(c) 


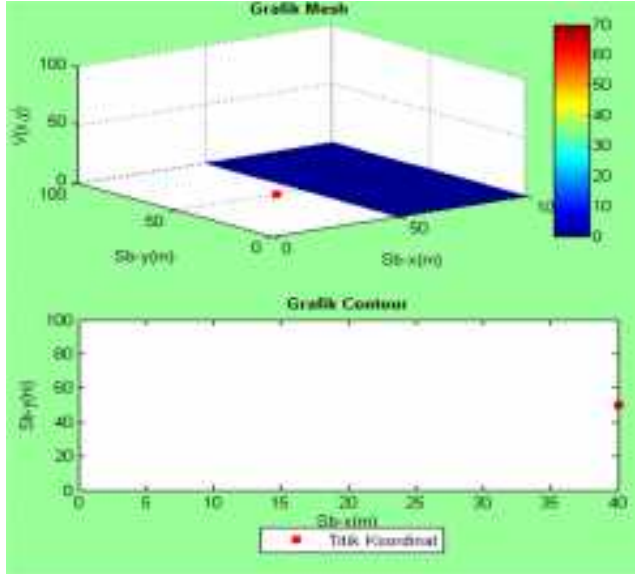

(d)

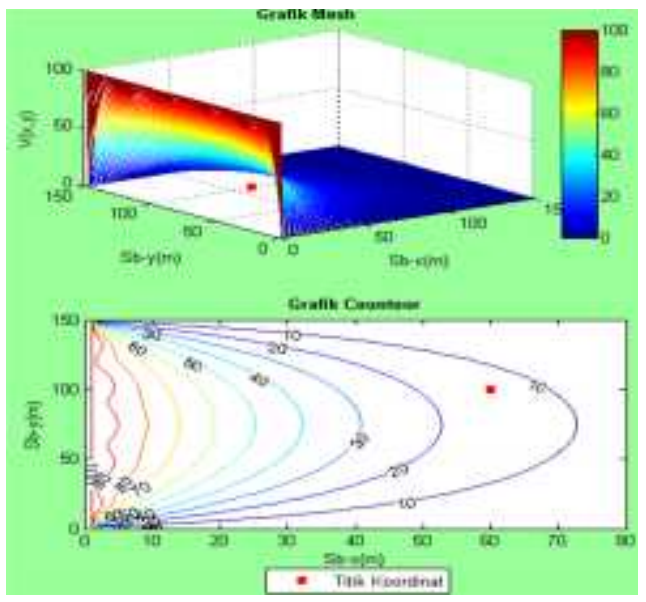

(e)

Gambar 4. Visualisasi potensial $\operatorname{listrik(a)}$ eksperimen I (b)eksperimen II(c) eksperimen III (d) eksperimen IV (e) eksperimen V.

Sesuai dengan syarat awal dan syarat batas yang diberikan, potensial listrik maksimum berada pada sumbu $x=0$, sementara pada sumbu $x$ dan $y$ maksimum serta sumbu $y$ minimum nilai potensial listrik adalah nol. Potensial listrik maksimum ditandai dengan warna merah tua, sementara potensial listrik paling kecil ditandai dengan warna biru tua.

Dari eksperimen I dan II terlihat bahwa nilai inputan $N$ yang besar memberikan keluaran grafik mesh yang lebih halus. Kemudian potensial listrik yang tidak terdefinisi pada eksperimen IV disebabkan oleh nilai lebar plat $(b)$ yang diinput jauh lebih besar daripada nilai jarak antar plat (a), sehingga persamaan yang digunakan pada penelitian ini yaitu persamaan menghasilkan keluaran berupa $\mathrm{NaN}$ (Not a Number).

\section{KESIMPULAN}

Program komputer yang telah dibuat dapat berjalan jika nilai parameter-parameter yang diinputkan pada program menu memberikan nilai iterasi yang sesuai pada program utama. Visualisasi potensial listrik diantara dua plat sejajar ditampilkan melalui grafik mesh dan contour, dimana warna merah tua menunjukkan potensial listrik maksimum dan biru. Semakin besar nilai grid yang diinputkan maka grafik mesh yang dihasilkan semakin halus. Solusi potensial listrik yang didapatkan pada penelitian ini tidak dapat digunakan jika nilai lebar plat jauh lebih besar dari nilai jarak antar kedua plat.

\section{UCAPAN TERIMAKASIH}

Penulis mengucapkan terima kasih kepada Prof. Dr. Erwin, M.Sc yang telah membimbing serta memberikan sumbangan pola pikir, waktu dan motivasi sehingga penulis dapat menyelesaikan karya ilmiah ini.

\section{DAFTAR PUSTAKA}

1. Reitz, J. R., Milford, F. J., \& Christy, R. W. (1979). Foundations of electromagnetic theory 3rd edition. Addison-Wesley Publishing Comp. Inc.

2. Hayt, W. \& Buck, J. (2001) Engineering electromagnetics six. edition. The McGraw Companies.

3. Supardiyono. (2011). Analisis Distribusi Suhu Pada Pelat Dua Dimensi Dengan Menggunakan Metoda Beda Hingga. Jurnal Penelitian Fisika dan Aplikasinya. Vol. 1 No. 2.

4. Griffiths, D. J. (1999). Introduction to electrodynamics 3rd edition. The United States of America: Reed College. 